Pacific Journal of Mathematics

DESIGNS IN AFFINE SPACES

William O'Bannon Alto 


\title{
5-DESIGNS IN AFFINE SPACES
}

\author{
W. O. AlLtoP
}

The $n$-dimensional affine group over $G F(2)$ is triply transitive on $2^{n}$ symbols. For $n \geqq 4,4 \leqq k \leqq 2^{n-1}$, any orbit of $k$-subsets is a $3-\left(2^{n}, k, \lambda\right)$ design. In this paper a sufficient condition that such a design be a 4-design is given. It is also shown that such a 4-design must always be a 5-design. A 5-design on 256 varieties with block size 24 is constructed in this fashion.

We shall call $(\Omega, \mathscr{D})$ a $t$ - $(v, k, \lambda)$ design whenever $|\Omega|=v, \mathscr{D}$ is a family of $k$-subsets of $\Omega$ and every $t$-subset of $\Omega$ is contained in exactly $\lambda$ members of $\mathscr{D}$. The design is nontrivial provided $\mathscr{D}$ is a proper subfamily of $\Sigma_{k}$, the family of all $k$-subsets of $\Omega$. If $G$ is a nontrivial $t$-ply transitive group acting on $\Omega$, then an orbit of $k$ subsets under $G$ yields a $t$-design. The design is nontrivial if $G$ is not $k$-homogeneous (transitive on unordered $k$-subsets). The first known 5-designs arose from orbits under the quintuply transitive Mathieu groups $M_{12}$ and $M_{24}$. Other 5-designs on 12, 24, 36, 48 and 60 varieties have been discovered (see [2; 3; 4]). In [1] a 5-design on $2^{n}+2$ varieties is constructed for every $n \geqq 4$. Here we shall discuss 5 -designs on $2^{n}$ varieties, giving one example for $n=8$.

Let $\Omega$ be an $n$-dimensional vector space over $G F(2), n \geqq 4$. Let $L$ be the linear group $G L(n, 2)$ acting doubly transitively on $\Omega-\{0\}$ and $T$ the group of translations $t_{\alpha}: \omega \rightarrow \omega+\alpha$. The group $A=\langle L, T\rangle$ is the triply transitive affine group on $\Omega$. Let $\Sigma_{4}, \Sigma_{5}$ denote the families of 4 -, 5 -subsets of $\Omega$ respectively. $\left(\Omega, \mathscr{S}_{0}\right)$ is a $3-\left(2^{n}, 4,1\right)$ design where $\mathscr{S}_{0}$ is the family of quadruples $\left\{\omega_{i}\right\}$ satisfying

$$
\omega_{1}+\omega_{2}+\omega_{3}+\omega_{4}=0 .
$$

$\mathscr{S}_{0}$ is the orbit of affine planes in $\Omega . \mathscr{S}_{1}$ is also an orbit, where $\mathscr{S}_{1}=\Sigma_{4}-\mathscr{S}_{0}$. Thus, $A$ decomposes $\Sigma_{4}$ into only two orbits. From the design parameters of $\left(\Omega, \mathscr{S}_{0}\right)$ one establishes that

$$
\begin{aligned}
& \left|\mathscr{S}_{0}\right|=\frac{1}{4}\left(\begin{array}{l}
2^{n} \\
3
\end{array}\right) \\
& \left|\mathscr{S}_{1}\right|=\left(2^{n-2}-1\right)\left(\begin{array}{l}
2^{n} \\
3
\end{array}\right) .
\end{aligned}
$$

Suppose $Q \in \mathscr{S}_{0}$. The stabilizer of $Q$ in $A$ is transitive on $Q-Q$. Thus, $\mathscr{T}_{0}$ is an orbit under $A$, where $\mathscr{T}_{0}$ consists of those members of $\Sigma_{5}$ which contain a member of $\mathscr{S}_{0}$. Now suppose $R \in \Sigma_{5}-\mathscr{T}_{0}$. 
Clearly there exists a translate of $R$ of the form

$$
R_{0}=\left\{0, \omega_{1}, \omega_{2}, \omega_{3}, \omega_{4}\right\} \text {. }
$$

Since $R_{0}$ contains no member of $\mathscr{S}_{0}$, the $\omega_{i}$ 's must be linearly independent in $\Omega$ considered as a vector space. Since $L$ is transitive on linearly independent quadruples in $\Omega-\{0\}$, it follows that $A$ must be transitive on the family $\mathscr{T}_{1}$, where $\mathscr{T}_{1}=\Sigma_{5}-\mathscr{T}_{0}$. Therefore, $A$ also decomposes $\Sigma_{5}$ into only two orbits. From our knowledge of $\left|\mathscr{S}_{0}\right|$ we can deduce that

$$
\begin{aligned}
& \left|\mathscr{T}_{0}\right|=\left(2^{n}-4\right)\left|\mathscr{S}_{0}\right|, \\
& \left|\mathscr{T}_{1}\right|=\frac{1}{5}\left(2^{n}-4\right)\left(2^{n}-8\right)\left|\quad \mathscr{S}_{0}\right| \cdot
\end{aligned}
$$

Geometrically $\mathscr{T}_{0}$ consists of the 5 -subsets which generate 3-dimensional affine subspaces of $\Omega$, while the members of $\mathscr{T}_{1}$ generate 4dimensional subspaces. This classification of orbits in $\Sigma_{4}$ and $\Sigma_{5}$ will provide the information needed to investigate 4 - and 5-designs which arise from orbits under $A$.

Suppose $\Delta$ is a $k$-subset of $Q$ and let $\mathscr{D}$ denote the orbit of $\Delta$ under $A$. Let $\sigma_{i}, \tau_{i}$ denote the number of members of $\mathscr{S}_{i}, \mathscr{T}_{i}$ contained in $\Delta$ respectively, $i=0,1$. Let $\lambda_{i}, \mu_{i}$ denote the number of members of $\mathscr{D}$ containing a fixed member of $\mathscr{S}_{i}, \mathscr{T}_{i}$ respectively, $i=0,1$. If $\lambda_{0}=\lambda_{1}\left(\mu_{0}=\mu_{1}\right)$, then $(\Omega, \mathscr{D})$ is a 4-design (5-design). The following equations relating the $\sigma_{i}, \tau_{i}, \lambda_{i}, \mu_{i}$ are the result of straightforward counting arguments:

$$
\begin{aligned}
& \sigma_{i}|\mathscr{D}|=\lambda_{i}\left|\mathscr{S}_{i}\right| \\
& \tau_{i}|\mathscr{D}|=\mu_{i}\left|\mathscr{T}_{i}\right| \\
& \tau_{0}=\sigma_{0}(k-4) .
\end{aligned}
$$

From (1) and the fact that

$$
\left|\mathscr{S}_{0}\right| /\left|\mathscr{S}_{1}\right|=1 /\left(2^{n}-4\right)
$$

we see that $(\Omega, \mathscr{D})$ is a 4 -design if and olyn if

$$
\sigma_{1}=\sigma_{0}\left(2^{n}-4\right) \text {. }
$$

Likewise from (2) and the fact that

$$
\left|\mathscr{T}_{0}\right| /\left|\mathscr{T}_{1}\right|=5 /\left(2^{n}-8\right)
$$

we see that $(\Omega, \mathscr{D})$ is a 5 -design if and only if

$$
\tau_{1}=\tau_{0}\left(2^{n}-8\right) / 5 \text {. }
$$


Since $\sigma_{1}=\left(\begin{array}{c}k \\ 4\end{array}\right)-\sigma_{0}$ and $\tau_{1}=\left(\begin{array}{l}k \\ 5\end{array}\right)-\tau_{0}$, we can use (3) to express $\sigma_{1}, \tau_{0}, \tau_{1}$ in terms of $\sigma_{0}$ and $k$. Substituting accordingly for $\sigma_{1}, \tau_{0}$, $\tau_{1}$ in (4) and (5) we obtain

$$
\begin{gathered}
\left(\begin{array}{c}
k \\
4
\end{array}\right)-\sigma_{0}=\sigma_{0}\left(2^{n}-4\right) \\
\left(\begin{array}{l}
k \\
5
\end{array}\right)-\sigma_{0}(k-4)=\sigma_{0}(k-4)\left(2^{n}-8\right) / 5 .
\end{gathered}
$$

After simplifying the preceding equations we see that both $\left(4^{\prime}\right)$ and $\left(5^{\prime}\right)$ are equivalent to

$$
\sigma_{0}=\left(\begin{array}{c}
k \\
4
\end{array}\right) /\left(2^{n}-3\right)
$$

We have in effect proved the following

TheOREM. $(\Omega, \mathscr{D})$ is a 5-design whenever $(\Omega, \mathscr{D})$ is a 4-design. $A$ necessary and sufficient condition for this to take place is that $\sigma_{0}=\left(\begin{array}{c}k \\ 4\end{array}\right) /\left(2^{n}-3\right)$.

The first thing to note is that $2^{n}-3$ must divide $\left(\begin{array}{l}k \\ 4\end{array}\right)$ for such a 5-design to exist. This is not possible for $6 \leqq k \leqq 2^{n-1}$ if $2^{n}-3$ is a prime power. Therefore, the first feasible value of $n$ is eight. For $n=8$, the values of $k \leqq 2^{7}$ for which $2^{n}-3$ divides $\left(\begin{array}{c}k \\ 4\end{array}\right)$ are 23,24 , 25, 46, 47 and 69. We pursue the case $n=8, k=24$.

Our theorem tells us that for $|\Delta|=24,(\Omega, \mathscr{D})$ is a 5 -design provided $\sigma_{0}=42$. We must select a 24 -subset $\Delta$ which contains exactly 42 members of $\mathscr{S}_{0}$. One example of such a $\Delta$ is the following. Let $\left(u_{1}, u_{2}, u_{3}, v_{1}, v_{2}, v_{3}, w_{1}, w_{2}\right)$ be a basis for the vector space $\Omega$. We define 3-dimensional vector subspaces of $\Omega$ :

$$
\begin{aligned}
& U_{0}=\left(u_{1}, u_{2}, u_{3}\right) \\
& V_{0}=\left(v_{1}, v_{2}, v_{3}\right) \\
& W_{0}=\left(u_{1}+v_{1}, u_{2}+v_{2}, u_{3}+v_{3}\right) .
\end{aligned}
$$

Now let $\Delta=U \cup V \cup W$, where

$$
\begin{aligned}
U & =U_{0}+w_{1} \\
V & =V_{0}+w_{2} \\
W & =W_{0}+\left(w_{1}+w_{2}\right) .
\end{aligned}
$$

For this $\Delta$ it is clear that $\sigma_{0} \geqq 42$ since each of the 3 -dimensional 
affine subspaces $U, V, W$ contains 14 members of $\mathscr{S}_{0}$. Suppose $\Delta$ contains additional members of $\mathscr{S}_{0}$. There exists $Q \in \mathscr{S}_{0}$ such that $Q$ meets at least two members of $\{U, V, W\}$. In order to decrease the number of cases to be considered we investigate the action of the stabilizer of $\Delta$ on $\{U, V, W\}$. Let $x, y \in L$ be defined by

$$
\begin{aligned}
& x:\left\{\begin{array}{l}
u_{i} \rightarrow v_{i} \rightarrow\left(u_{i}+v_{i}\right) \rightarrow u_{i}, \quad 1 \leqq i \leqq 3 \\
w_{1} \rightarrow w_{2} \rightarrow\left(w_{1}+w_{2}\right) \rightarrow w_{1}
\end{array}\right. \\
& y:\left\{\begin{array}{l}
u_{i} \rightarrow v_{i} \rightarrow u_{i}, \quad 1 \leqq i \leqq 3 \\
w_{1} \rightarrow w_{2} \rightarrow w_{1} .
\end{array}\right.
\end{aligned}
$$

Letting $x^{*}, y^{*}$ denote the action of $x, y$ on $\{U, V, W\}$, we have

$$
\begin{array}{ll}
x^{*}: & U \rightarrow V \rightarrow W \rightarrow U \\
y^{*}: & U \rightarrow V \rightarrow U, \quad W \rightarrow W .
\end{array}
$$

Hence, $\left\langle x^{*}, y^{*}\right\rangle$ acts as the symmetric group $S_{3}$ on $\{U, V, W\}$. We must only consider the cases where the partition of $Q$ induced by $(U, V, W)$ is of the form $(2,2,0),(3,1,0)$ or $(2,1,1)$. These three cases are easily seen to be impossible, so no such $Q$ exists. It follows that $\sigma_{0}=42$, and we have a 5 -design on 256 varieties with blocks of size 24.

One wonders in how many affine spaces $\Omega$ such 5-designs exist. Since 143 divides $2^{n}-3$ whenever $n \equiv 28(\bmod 60)$, there are infinitely many values of $n$ for which $2^{n}-3$ is not a prime power. For fixed $k$, $n$, with $6 \leqq k \leqq 2^{n-1}$, let us consider the problem heuristically. Suppose we select $\Delta$ from $\Sigma_{k}$ randomly, each member of $\Sigma_{k}$ having probability $1 /\left(\begin{array}{c}2^{n} \\ k\end{array}\right)$ of being selected. Now $\sigma_{0}$ is a random variable on the probability space $\Sigma_{k}$. The expectation of $\sigma_{0}$ is

$$
E=\left(\begin{array}{c}
k \\
4
\end{array}\right) /\left(2^{n}-3\right) \text {. }
$$

A 5-design of the type under consideration exists if and only if $\sigma_{0}$ achieves its expectation in $\Sigma_{k}$. When $E$ is an integer, it does not seem unreasonable that $\sigma_{0}$ would achieve its expectation.

The author has not investigated the construction of designs in affine spaces over $G F(2)$ by using more than one orbit under A.

\section{REFERENCES}

1. W. O. Alltop, An infinite class of 5-designs, to appear.

2. E. F. Assmus, Jr., and H. F. Mattson, Jr., New 5-designs, J. Combinatorial Theory, 6 (1969), 122-151.

3. D. R. Hughes, On t-designs and groups, Amer. J. Math., 87 (1965), 761-778. 
4. Vera Pless, On a new family of symmetry codes and related new 5-designs, Bull. Amer. Math. Soc., 75 (1969), 1339-1342.

Received February 16, 1970. Part of the results in this paper were presented to a meeting of Navy Mathematicians at Colorado State University, Fort Collins, Colorado, August 20, 1970.

Michelson Laboratories, China LaKe, California 



\title{
PACIFIC JOURNAL OF MATHEMATICS
}

\author{
EDITORS
}

\author{
H. SAMELSON \\ Stanford University \\ Stanford, California 94305 \\ C. R. HOBBY \\ University of Washington \\ Seattle, Washington 98105
}

J. DugundJI

Department of Mathematics

University of Southern California

Los Angeles, California 90007

RICHARD ARENS

University of California

Los Angeles, California 90024

\section{ASSOCIATE EDITORS}
E. F. BeCKenBaCH
B. H. NeUMANN
F. WOLF
K. Yoshida

\section{SUPPORTING INSTITUTIONS}

\author{
UNIVERSITY OF BRITISH COLUMBIA \\ CALIFORNIA INSTITUTE OF TECHNOLOGY \\ UNIVERSITY OF CALIFORNIA \\ MONTANA STATE UNIVERSITY \\ UNIVERSITY OF NEVADA \\ NEW MEXICO STATE UNIVERSITY \\ OREGON STATE UNIVERSITY \\ UNIVERSITY OF OREGON \\ OSAKA UNIVERSITY
}

\author{
UNIVERSITY OF SOUTHERN CALIFORNIA \\ STANFORD UNIVERSITY \\ UNIVERSITY OF TOKYO \\ UNIVERSITY OF UTAH \\ WASHINGTON STATE UNIVERSITY \\ UNIVERSITY OF WASHINGTON \\ AMERICAN MATHEMATICAL SOCIETY \\ NAVAL WEAPONS CENTER
}

The Supporting Institutions listed above contribute to the cost of publication of this Journal, but they are not owners or publishers and have no responsibility for its content or policies.

Mathematical papers intended for publication in the Pacific Journal of Mathematics should be in typed form or offset-reproduced, (not dittoed), double spaced with large margins. Underline Greek letters in red, German in green, and script in blue. The first paragraph or two must be capable of being used separately as a synopsis of the entire paper. The editorial "we" must not be used in the synopsis, and items of the bibliography should not be cited there unless absolutely necessary, in which case they must be identified by author and Journal, rather than by item number. Manuscripts, in duplicate if possible, may be sent to any one of the four editors. Please classify according to the scheme of Math. Rev. Index to Vol. 39. All other communications to the editors should be addressed to the managing editor, Richard Arens, University of California, Los Angeles, California, 90024.

50 reprints are provided free for each article; additional copies may be obtained at cost in multiples of 50 .

The Pacific Journal of Mathematics is published monthly. Effective with Volume 16 the price per volume (3 numbers) is $\$ 8.00$; single issues, $\$ 3.00$. Special price for current issues to individual faculty members of supporting institutions and to individual members of the American Mathematical Society: $\$ 4.00$ per volume; single issues $\$ 1.50$. Back numbers are available.

Subscriptions, orders for back numbers, and changes of address should be sent to Pacific Journal of Mathematics, 103 Highland Boulevard, Berkeley, California, 94708.

PUBLISHED BY PACIFIC JOURNAL OF MATHEMATICS, A NON-PROFIT CORPORATION

Printed at Kokusai Bunken Insatsusha (International Academic Printing Co., Ltd.), 270, 3chome Totsuka-cho, Shinjuku-ku, Tokyo 160, Japan. 


\section{Pacific Journal of Mathematics}

\section{Vol. 39, No. $3 \quad$ July, 1971}

William O'Bannon Alltop, 5-designs in affine spaces ................... 547

B. G. Basmaji, Real-valued characters of metacyclic groups ................. 553

Miroslav Benda, On saturated reduced products....................... 557

J. T. Borrego, Haskell Cohen and Esmond Ernest Devun, Uniquely representable semigroups. II.......................................

George Lee Cain Jr. and Mohammed Zuhair Zaki Nashed, Fixed points and stability for a sum of two operators in locally convex spaces ....................

Donald Richard Chalice, Restrictions of Banach function spaces ...............

Eugene Frank Cornelius, Jr., A generalization of separable groups ..............

Joel L. Cunningham, Primes in products of rings ......................

Robert Alan Morris, On the Brauer group of $Z$.

593

603

615

David Earl Dobbs, Amitsur cohomology of algebraic number rings ...............

Charles F. Dunkl and Donald Edward Ramirez, Fourier-Stieltjes transforms and

weakly almost periodic functionals for compact groups ...................

Hicham Fakhoury, Structures uniformes faibles sur une classe de cônes et

d'ensembles convexes ......................................

Leslie R. Fletcher, A note on C $\theta \theta$-groups.

Humphrey Sek-Ching Fong and Louis Sucheston, On the ratio ergodic theorem for

semi-groups............................................

James Arthur Gerhard, Subdirectly irreducible idempotent semigroups ...........

Thomas Eric Hall, Orthodox semigroups.....................

Marcel Herzog, $C \theta \theta$-groups involving no Suzuki groups ..........

669

687

John Walter Hinrichsen, Concerning web-like continua ..........

691

Frank Norris Huggins, A generalization of a theorem of F. Riesz.

695

Carlos Johnson, Jr., On certain poset and semilattice homomorphisms

703

Alan Leslie Lambert, Strictly cyclic operator algebras ...........

717

Howard Wilson Lambert, Planar surfaces in knot manifolds . . .

727

Robert Allen McCoy, Groups of homeomorphisms of normed linear spaces ....... 735

T. S. Nanjundiah, Refinements of Wallis's estimate and their generalizations ...... 745

Roger David Nussbaum, A geometric approach to the fixed point index .......... 751

John Emanuel de Pillis, Convexity properties of a generalized numerical range .... 767

Donald C. Ramsey, Generating monomials for finite semigroups ....

783

William T. Reid, A disconjugacy criterion for higher order linear vector differential equations...

Roger Allen Wiegand, Modules over universal regular rings...

Kung-Wei Yang, Compact functors in categories of non-archimedean Banach

spaces.

R. Grant Woods, Correction to: "Co-absolutes of remainders of Stone-Čech compactifications".

Ronald Owen Fulp, Correction to: "Tensor and torsion products of

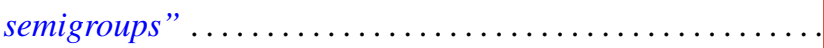

Bruce Alan Barnes, Correction to: "Banach algebras which are ideals in a banach 